Citation: P. Landri (2021) The (ir)resistible acceleration of digital education. The emergence of the blended school form in a state of education emergency. Media Education 12(2): 5-14. doi: 10.36253/me-12334

Received: November, 2021

Accepted: November, 2021

Published: December, 2021

Copyright: (c) 2021 P. Landri. This is an open access, peer-reviewed article published by Firenze University Press (http://www.fupress.com/me) and distributed under the terms of the Creative Commons Attribution License, which permits unrestricted use, distribution, and reproduction in any medium, provided the original author and source are credited.

Data Availability Statement: All relevant data are within the paper and its Supporting Information files.

Competing Interests: The Author(s) declare(s) no conflict of interest.

\section{The (ir)resistible acceleration of digital education. The emergence of the blended school form in a state of education emergency}

\author{
L'(ir)resistibile accelerazione dell'educazione digitale. \\ L'emergenza della didattica mista in uno stato di emergenza \\ educativa
}

\author{
PAOLO LANDRI \\ CNR-IRPPS \\ p.landri@irpps.cnr.it
}

\begin{abstract}
This article focuses on the recent acceleration of digital education triggered by the Covid19 pandemic. Protective measures, particularly the social distancing, translated into an institutional shock for the standard form of schooling. By drawing on a summary of current investigations on the topic (Brehm, Unterhalter \& Oketch, 2021; Grek \& Landri, 2021), the article describes how swift digitalization has reinforced the entanglement of public education into private owned and commercial platforms and paved the way to the emergence of the blended school form. The instabilities of the current process of institutional repair are underlined together with the risk of increasing unbalanced private and public partnership in the education system, and/ or returning to the standard form of schooling in the future post-pandemic scenario.
\end{abstract}

Keywords: acceleration, blended schooling, digitalization, school morphology, soft privatization

Riassunto. Il presente contributo si concentra sulla recente accelerazione delleducazione digitale innescata dalla pandemia di Covid19. Le misure di protezione, in particolare il distanziamento sociale, si sono tradotte in uno shock istituzionale per la forma standard di scolarizzazione. Attingendo a una sintesi delle ricerche in corso sullargomento (Brehm, Unterhalter \& Oketch, 2021; Grek \& Landri, 2021), l'articolo descrive come la rapida digitalizzazione abbia rafforzato l'intreccio dell'istruzione pubblica con le piattaforme commerciali, private, e abbia aperto la strada alla nascita della scuola mista. Il lavoro evidenzia le instabilità dell'attuale processo di risanamento istituzionale, insieme al rischio di aumentare il disequilibrio tra pubblico e privato nel sistema educativo, e/o il ritorno alla forma standard di scolarizzazione nel futuro scenario post-pandemia.

Parole chiave: accelerazione, didattica mista, digitalizzazione, morfologia scolastica, privatizzazione soft. 


\section{INTRODUCTION}

The institutional shock triggered by the pandemics and the measures for social distancing for schools and universities has been partly absorbed through the acceleration of digital education. Digital platforms are becoming 'the new magic' to change education radically: a widespread sense of inevitability, inspired by 'technological solutionism' (Morozov, 2019), seems to characterize the dominant regimes of policy, but also the most important research approach on the topic.

International investigation on the Covid19 impact on education, however, depicts complex and nuanced scenarios. Digitalization of education in the EU was forced in a situation of emergency and appeared far from being univocal. EU countries are faced with emergency education in different ways. It is hard to predict whether the digital acceleration will lead to a significant turning point in school morphology. The pandemics led to the experimentation of digital school forms, but it is difficult to say whether the classic forms of schooling will be substituted or simply repaired. Instead, there is the possibility of a rejection of the most radical experiments of digital schooling and the return to its standard form, despite the chance of reinvention offered by the pandemics. The standard form of schooling seems to have a notable capacity for reproduction despite the novelty of the digital. There is a need then to understand the dynamics of the morphology of schooling and to analyze the likely impact of digitalization critically.

In this article, I will summarize some recent research findings on European education in times of pandemic (Cone et al., 2021; Grek \& Landri, 2021). In so doing, I will draw attention to the installation of a new education state of emergency through a regime of fast policy and on experimentation of new forms of schooling. Firstly, I will illustrate how digitalization enacts a complex and fragile reassembling of discourses, technology and people that reinforce the embeddedness of the public education governance into private technologies and commercially driven platforms (Cone et al., 2021) (Cone \& Brøgger, 2020). Secondly, I will reflect on how this acceleration is affecting the changing morphology of schooling. While two spatial reconfigurations are emerging and are partly experimented with: the 'purely digital' and the 'blended school' forms, the standard model of school has not been discarded. The Italian case will be helpful to show the potentialities and the tensions of the blended school form (Grimaldi, Landri, \& Taglietti, n.d.) that is far from being stabilized.

\section{DIGITAL EDUCATION IN A STATE OF EDUCATION EMERGENCY}

The social distancing, the measures for preventing the spreading of Covid19, the attempts to find a way to cope with the pandemics has provoked a state of radical uncertainty for contemporary societies. It has altered the normality and, notably, the foundations of institutions. Institutions are means to cope with uncertainty by offering meanings and confirming the social construction of reality. They are mechanisms to which are delegated the 'whatness of what it is'; they have semantic and pragmatic tasks (Boltanski, 2011). Pandemic deeply troubles the precarious certainty they offer. The impossibility of making school in the usual way affected, therefore the school as an organization, and as an institution. In that situation of emergency, digital devices, platforms, software, etc., offered an immediate solution for the education systems.

The transition to the digital was swift: it appeared the only possibility to have a form of schooling in times of pandemic. This 'immediate' shift was not surprising; it was, in some way, prepared by the investment in the digital governance of education of the latest years. Due to the large investments in digital infrastructures, software, datafication, and in the 'platformization' of education following the changes in the current configuration of the governance and the systems of accountability, the 'digital' has become taken for granted for twenty years. As codes, infrastructures, algorithms, platforms, artefacts for collecting, visualizing, and storing data, etc. (Landri, 2018; Souto-Otero \& Beneito-Montagut, 2016; Williamson, 2016) are the new building blocks for augmenting the ecology of education practice and transforming education as a space of increasing interconnectedness there is little surprise that the digital solutions were immediately seen, taken and generalized in time of emergency. The digital world appears to provide a set of possibilities to making education in safe conditions. It permitted to leave open schools in the absence of the corporeal presence.

In principle the digital was seen as the solution, the concrete trajectories of the emergency education in different EU countries, however, appeared quite different. In a recent special issue edited in collaboration with Sotiria Grek and published in the European Educational Research Journal, we have collected a set of histories of the present about European education and Covid19 (Grek \& Landri, 2021). Further articles have been published in the same journal that permitted to give an overall description of how education systems in the EU moved to digital solutions to give wide descrip- 
tions of the many instantiations of the state of education emergency. In confronting with the pandemic, the soft governance based on the networked globalization was supplanted by the return of the sovereignty of the state. Governments became the sole decision-makers, by drawing on a complex bio-medical-statistical expertise mobilized to set up the informational basis of the political choices. A fast regime of governance emerged in the policy-making arenas interconnecting live data health, digital infrastructures, medicine, statistics. (Kelly, Hofbauer \& Gross, 2021; Lindblad et al., 2021; Milner, Mattei, \& Ydesen, 2021; Mitescu-Manea et al., 2021). Cosmopolitan approach appeared suddenly dangerous, and the preoccupation for immunization dominated the public discourse with the closure of 'borders' to the 'foreigners' seen as potential allies for the virus spreading. Transnational actors were temporarily less influential in the emergency national decisions (EU Pact for Stability and Growth was suspended). At the same time, there was an almost immediate turn to the digitalization of education. A brief summary of the situation in Germany, Belgium, Sweden, Italy (Cone et al., 2021) is helpful to understand the diversities but also the common trends in the digitalization emergency during the pandemic. As we will see, the pandemic is an accelerator of existing processes, more than a radical change maker (Tesar, 2020).

Digital education reforms and investments were more significant in the case of Scandinavian countries and the UK, also mirroring a strong commitment toward the digitalization of the societal configurations ${ }^{1}$. Germany appears, on the contrary, among the countries more reluctant to invest widely in the digital as to school. The reasons concern the governance of the system, the attitude towards the Ed-tech companies and the professional field. As to the first aspect, there is a complex architecture of the education system due to the federal configuration. Not only do states present diverse configurations, but there is also a complex distribution of authorities between the state and the local level. Secondly, scepticism is diffuse when it comes to the for-profit actors in education. Public institutions maintain the responsibility for the running of the system, and there is a practice of subcontracting that produce a high fragmentation of the 'markets' of education, as to the datafication, external testing, etc. As a result, there is less space for Ed-tech companies. Only in 2016 digital education become a national policy priority, and it was agreed in 2019 the DigitalPakt foster digitalization in schools. The slow implementation of the reform confirmed the reluctance toward the digital and raised the

${ }^{1}$ See for example the DESI Index https://digital-strategy.ec.europa.eu/ en/policies/desi preoccupation, mainly from Ed Tech providers, that the German education system needed to be radically transformed to meet the international standards. The lack of hardware, software and skills for dealing with the setting up of a digital emergency education during the mass school closure supported the view of an education scenario in crisis and pushed Ed-Tech companies to provide solutions. Free software, hardware, short webinars, learning management systems expanded temporarily for free. Help desks, tutorials, etc., accompanied the diffusion of digital systems. Big Ed-Tech companies, but also school book publishers accordingly made available their products and mobilized their marketing strategies. The Federal Ministry of Education and Research considered the Covid19 crisis a window of opportunity for supporting the digitalization, by making operational the school funding. These investments created then the conditions for the unfolding of a nationwide market for Ed-Tech companies. The Federal Ministry, however, was active also in promoting state-led, non-profit alternatives, like Schul-Cloud, which is an LMS widely advertised during the school lockdown. In sum, the development of publicprivate partnerships characterized the acceleration of the digitalization of schooling in Germany. It is difficult to say how these partnerships will unfold: whether it will lead to asymmetries or to balanced public-private relationships in the field.

While Germany appears reluctant, Sweden already, before the pandemic, had significantly invested in the digitalization of schooling. Here, a national strategy designed in collaboration with Ed Tech providers was already effective for several years. The pandemic permitted the consolidation and the development of a digital market in education. Despite the other EU countries, Sweden maintained the school open to the physical presence for the students under the age of 16. Upper secondary schools, universities, etc., went online overnight. At the same time, the uncertainty of the time put strong pressure even on the other grades of education to set up digital infrastructures. The role of the Swedish Edtech Industry (SEI) has been particularly important in playing the role of promoter of digitalization in schooling. SEI was important as it connected private companies to the public customer, carried out lobbying activities, and acted as a 'connector' for the Nordic countries and Europe. During the pandemic, SEI was able to become a legitimate actor in the management of the crisis by offering information and providing a list of Ed-tech enterprises available to fix emerging problems in schools. Its website included a list of free resources, additional services, webinars for teacher training, links to companies for the substitution of staff in case of temporary sick 
vacancies. With the Ed-tech thermometer measuring the capacity of the education system to furnish solutions to the education emergency and the list of resources for school, SEI offered services and products for schools of different grades. The association played a fundamental role in making the digital an essential ingredient of the post-pandemic scenario of Swedish schooling. His capacity to open up the field to profitable capitalistic investments was countered by the use of a philanthropic discourse underlying altruism in a time of crisis. SEI prepared, therefore, the future scenario of instruction, beyond the Covid19 emergency, by making the digitalization the new permanent territory for the Swedish schools. In this new scenario, the complex entanglement of public institutions and private companies become the basic infrastructure of the educational system.

Even the case of Italy confirms a trend towards soft privatization, that is, the enlargement and the consolidation of private and public partnerships to support digitalization. Like Germany, however, Italy was not at the forefront of digital education. ICT equipment in schools was lagging behind most OECD countries. Teachers were reluctant to move towards the use of digital devices, regardless of some notable exceptions. The pandemic, however, hit the country severely, and, as the preventive measures made it extremely difficult, the continuity of the standard model of schooling opened the door to a big acceleration of the platformization of education. Government, media, public intellectuals urged to shift rapidly to the massive strategy of digitalization that was seen as the only way to deal with the impossibility to guarantee a 'safe environment' for school. Discursively, it was invented 'didactics at a distance' with the increasingly popular acronym 'DAD' that inspired several policies and guidelines. At the same time, a sense of solidarity towards the young generation informed the activation of public and private partnerships to fill the gap provoked by the impact on the schooling of the Covid19. This discourse gives rise to the Ministry of Education's Distance Education Initiative, a policy aimed at providing resources and information on the possibilities of digital teaching and education during the school closure. By drawing on a website, this initiative listed webinar series, conferences and tools freely available for schools of any grade. Best practices were presented, introduced and discussed. Three learning management systems were soon offered, followed by others, consisting of Google Suite for Education, Microsoft Teams $365 \mathrm{Al}$ and We School, a platform provided by TIM, the most important Italian corporation in the field of information and communication technology. Thanks to DEI, Google, Microsoft and Tim increased their visibility. Microsoft offered free Office 365 Al ser- vices and assistance to schools; TIM provided access to We school, a digital classroom platform with one year card for several related MIUR software and application; Google through two Italian intermediaries, C2Group and Campus Store, offered similar services. The rhetoric of disruption accompanied this shift: the new technologies promised to change teaching and learning practices completely. A contrast was presented among the constrained space of the traditional classroom and the possibilities of a borderless education conveyed by the digital devices, software and platforms. This trend should be considered in a longer process of re-acculturation of the educational system concerning its pedagogical, curricular and evaluative building blocks prior to the emergency. The pandemic has acted rather as a window of opportunity for accelerating the process. The clever strategy of the big companies has granted the setting up of a de facto oligopolistic cartel. As a consequence, they have become an 'obligatory point of passage' in the technical infrastructure of the schools. By consolidating their presence in public and private relationships in which it is now embedded the Italian education system, that they are destined to play a major role in the post-pandemic scenario.

While the dominant tendency in the swift passage to digital emergency education in Germany, Sweden, Italy, but also in other European countries, aligned with soft privatization, this process has no unique direction. The case of Belgium permits us to see the possibilities of alternative developments. Here, with school closures, there was an increase in the popularity of KlasCement, a platform supported by the Flemish government. The platform hosts, share, gives access to any kind of educational materials elaborated by educational actors, even commercial companies, without monetary returns. KlasCement was created by a single teacher in 1998 and since 2013 has been sustained by the Flemish government. Initially, it was a website for one school; then, it became a locus of meeting for other schools, teachers, students. The governmental support allowed its expansion in terms of scope, quantities of educational materials as well as the audiences it was able to reach. School closure sets the condition for its exponential growth. The platform followed the governmental guidelines suggesting the method of pre-teaching. Educational materials were uploaded, and it was offered to students in advance in the perspective of the school reopening. Moreover, the platform enlarged the audience by including parents. Originally designed for schools and professionals, KlasCement invited parents explicitly in a time where emergency education meant, in many cases, the shift from standard school to home-schooling. It is not clear how it will happen when the pandemic crisis is 
over, and notably, whether the platform will remain an important point of reference for Flemish schools. Nevertheless, there was a commitment from the government to support it as a 'unique platform' and consider its contribution to open-source teaching. With respect to the privately-owned platforms, KlasCement promotes the communalization of the educational materials: it is inspired by a logic of collaboration in the making of digital resources and tools that in turn produces a network effect as the logic of co-construction seems to invite others to join a collective endeavour. The platform is a collector of materials but also a facilitator of discussions that, particularly during the first lockdown, ease the exchange of experience and expertise at a distance. Moreover, the platform operates a standardization of the materials that require staff members, recruited mainly among teachers. Materials are manually and algorithmically curated. This operation allows the emergence of some hierarchies among the contributors that was partly mitigated by the standard format that remains the same and does not give privilege to some providers (for example, big Ed-Tech companies) at the expense of others. KlasCement illustrates that the acceleration of the digital platform in the pandemic does not necessarily lead to the reinforcement of the private enterprises and the weakening of the public regulations. While it fosters the unfolding of public and private relationships, it does not end up in accentuated asymmetries. It can happen through collaboration and without undermining the agency of teachers and educational professionals.

These four cases demonstrate that the move toward the digitalization that develops overnight because of the emergency accentuates existing processes, more than provoking a sudden reinvention of the institution. The 'digital' offered an immediate solution for the continuity of the school. This shift occurred through private and public partnerships, leading to the trajectory of soft privatization of the educational systems. These partnerships pre-existed to the pandemic, or they were facilitated by the crisis. Processes of soft privatization were already in progress in Sweden and in Italy, while the pandemic helped to circumvent the reluctance to the digital in the case of Germany. These partnerships can be variable; that is, they can be balanced or not. Ed Tech 'giants' (like Google, Microsoft) are often successful in positioning themselves as key actors in the ecology of education systems. Regardless of the dominant trend, there is some room for alternative possibilities, like in the case of Belgium. The digital platform may be done collaboratively and outside an extractive logic. The public may play a regulatory role and promote an active engagement of school and educational professionals. This alternative, however, was cultivated before the pandemic and found in the crisis an opportunity for thriving. The sudden break of Covid19 in schooling was repaired by the reliable solutions available in the repertoire of possibilities of each education system.

\section{CHANGING MORPHOLOGIES. THE EMERGENCE OF THE BLENDED SCHOOL FORM IN THE AFFLUENT COUNTRIES.}

In this section, I will consider to what extent the acceleration of the digital in times of pandemic has affected the morphology of schooling, that is, whether the massive use of digital platforms and devices has altered the grammar of schooling. It is well known that there is a large amount of scientific literature on the form of school (Maulini \& Perrenoud, 2005; Tyack \& Tobin, 1994). This scholarship underlines how this form consists in the creation of a bounded space, a space of education practice clearly separated by the social and economic practices it is aimed to prepare. The form of school set up a border between the real or the authentic practice from the training of a practice. The training consists of a set of rules, protocols, standards and of an asymmetry between teachers and students, between the knowledgeable and the learner who knows less or nothing. Eight features are the main characteristics of the grammar of schooling: a) the contract between teachers and students; b) an organizational configuration; c) the separation between the 'real' practice and the educational practice; d) the prefiguration of the activity to be learned and the definition of a learning curriculum; e) the educational translation of knowledge; f) a time for education g) the discipline; $h$ ) the setting of educational standards. This grammar has become the widely accepted form for schooling in many systems of education, and while it is specific for basic and compulsory education, it has also been implemented in other levels of education, like adult education or business school. This configuration has manifested a notable persistence over time so that it appears for some 'the' basic structure of the school, almost a second nature, despite these characteristics emerging historically with the institutionalization of mass schooling. As we have seen, the pandemic sets the condition for a problematization of this form and open the way to some experimentations.

The emergency teaching was varied: it included the interactivity online, but also the use of TV and radio. While interactive online education was adopted in the richest countries, in some of the poorest countries in the world, there was no substitute teaching at all. Only 19\% of households had internet access in Sub-Saharan Africa 
in comparison with $89 \%$ in North America. A similar percentage concerned TV and radio ownership. Access and quality of emergency education were unequal within and across countries (Brehm et al., 2021). In those countries where the shift to the digital occurred overnight, two reconfigurations of the form of school have been experimented with: purely digital and blended schooling.

In some countries, school closure led to purely digital schooling. This form, however, was seen immediately as problematic and was limited in time and level of education. It appeared sustainable only for the upper secondary school and the university.

In particular, purely digital schooling is equivalent to a shift towards home-schooling. This movement risks exacerbating social inequalities. In their secondary analysis of the $2^{\text {nd }}$ survey on ICT and education carried out by the European Commission in 2019, Dimopoulos, Koutsampelas \& Tsatsaroni (2021) tried to illustrate the likely effect of the shift to home-schooling via digital platforms. Their findings underline how parents' familiarity with ICT and education-related use of ICT are higher for highly educated than for low educated families. This result is consistent across European countries: it means that low educated families are more likely to set unfavourable conditions for learning in home-schooling. A detailed study on parenting practices in high socioeconomic families in France allows us to understand why in that case, home-schooling during lockdown was not an issue (Delès, 2021). What makes the difference is the way these families were able to mobilize their resources to compensate for the school closure. One strategy was to recreate a 'mini-school', that is, reconfiguring the space and time of the family to re-install the school at home. Time-tables for school activities are formalized and explicated. Work and free time are balanced. Proper space is devoted to educational events. The possibilities of assign, and reconfiguring the family space to mirror a school space is related to housing inequalities. In low socio-economic families, houses are often overcrowded so that the space is shared. On the contrary, broader family space in high socio-economic classes provides additional resources. The family support is not limited to furnishing a framework in which to study. It also concerned the study in itself. A second strategy regards the assistance provided by high socioeconomic families for learning. A varied pedagogy is assumed, consisting in the proposal of complex exercises and of alternative teaching resources. Enhanced reflexivity is promoted, leading to troubling the basic epistemology of the school and revealing its expectation. These two strategies are finally complemented by an overall atmosphere that helps to cope with the inevita- bility of effort in learning and makes the routine aspect of schooling more acceptable.

While these mechanisms have been already described in other investigations, the school closure makes visible that the 'digital' per se does not intervene in a straightforward way on the educational inequalities that ultimately depend on the family backgrounds, and in particular, on the differential family resources. The likely impact of inequalities made the possibilities of the generalization of a purely digital form of schooling quite remote. However, it can be noted that it is still present as an underlying idea in some exercises about the future scenario of education ${ }^{2}$.

More feasible appears the blended school form: here, the bodily presence mixes with the possibilities of the digital. The acceleration of the platforms in schools, the forced training of school staff, the investment in technical infrastructure tended to generalize an idea that prior to the pandemic was interesting, but still the experimentation of few. As far as the dynamics of the outbreak permitted and the orientation to leave open schools in primary education prevailed in many countries, this morphology became more and more popular. Apparently, the blended formula offers a fair compromise. In practice, it is still unstable. In order to reveal the epistemic dimensions of this transformation, it is useful to map the discourses in Italy, a country where Covid19 hit severely and where school closure was more rigid than elsewhere. By drawing on archaeological analytics, it is possible to describe the clashes and the encounters of multiple discourses around the blending of schools (Taglietti, Landri, \& Grimaldi, 2021).

The 'blending' emerges in the reconfiguration of the discourses around space, time and subjectivities of school. The re-spatialization occurs between two forms of rationality, the 'Developmentalizing' and the 'Securing'. The first one is the classic logic of schooling that tend to design a space aimed at intervening on the bodies to improve and enhance them; the second one, on the contrary, intends to make space for immunization. The goal of immunization reveals the link established between school and health: school becomes a medicalized locus, that is, a place reshaped by new health protocols. At the same, the digital is mobilized for the development of the social body. The rhetoric of innovation here suggests how the digital permits to keep open the school despite the pandemic. It allows to continue educational activities beyond the standard school space and

\footnotetext{
2 See the 'learn-as-you-go scenario in OECD (2020), Back to the Future of Education: Four OECD Scenarios for Schooling, Educational Research and Innovation, OECD Publishing, Paris, https://doi. org/10.1787/178ef527-en
} 
to guarantee the work of teaching and learning aimed at acquiring and refining skills and competencies. In some cases, the two rationalities collapse in the discourses giving rise to complex reconfigurations. The logic of immunization may have the priority so that schooling may appear spaces of retention or may completely integrate the digital in the dynamics of development, like in the discourse of lifelong learning or the policies of the promotion of skills and competencies. In the case of Italy, the passage towards integrated digital teaching during the pandemics was a sign of the full inclusion of digital platforms and devices in the ordinary educational offer. Notably, the guidelines prepared by the Ministry were intended to bring to the fore how the digital could contribute to the developmental logic of schooling during emergency education.

Yet, the digital also reshapes the temporality of educational activities in school. At the same time, there is still the heritage of the standard time of the schooling, the discourses displaying a growing awareness of the multiplication of temporalities made possible by the digital. Discourses are articulated around 'The Time' and 'The Times'. Pandemics have opened a debate about the future of education and stimulated discussion on the school in 'new' normality. Particularly active in that respect have here the international organizations, like UNESCO, OECD, World Bank. On the one hand, there is a tendency to define a linear temporality, where there is a past and one future to be identified; on the other hand, there are many futures at stake and diverse temporalities, 'The Times'. The multiplication of times makes school hours 'volatile'; the slot of time is not necessarily related to the 'one-hour lesson' but more oriented to the 'study'. Multiple times made possible by the digital makes aware of the need for tailored governance of schools and the decline of 'The Time' of schooling (Nóvoa \& Alvim, 2020). The shift to multiple temporalities occurred in the mixing of online and bodily presence teaching and learning when there was the partial reopening of schools after the rigid lockdown. Here, we have the composition of the digital teaching with teaching in presence, which also meant the problematic coexistence of digital and bodily presences. To some extent, 'The Time' faces a partial pluralization. There is not a unique time but a composition of temporalities that require a careful and planned linear re-composition. Notably, 'the blended-school form is shaped by the multiplication of normalized, linear and quantified temporality, attempting to plan lives and to discipline students, by creating their 'new [multiple and blended] routines' (Taglietti et al., 2021).

The blended school form, finally, promises to intervene on subjectivities. The discourses here focus on two poles: 'the Individual' and the 'Population'. The dualism concerns the single persons to be mobilized, controlled, disciplined from the outside, and the population, considering groups, categories of subjects, etc. Teachers and students are seen as populations of 'digital teachers' and 'digital students'. Digital platforms and devices are intended as vehicles for the circulation of emotions, feeling and affects. Digital education, in that case, is seen as a way to develop for a larger population a better curriculum and at the same time to nurture the professional repertoire of schools. There was, however, various mixing between the individual and the population. A categorization of population led to group together people suffering most by the sudden shift to the digitalization: 'poor children', 'boys and girls in vulnerable situation', 'families with less socio-economic resources'. Intergovernmental agencies and national agencies of the government were active to draw on the notion of 'learning loss' to identify those groups and to propose personalized educational activities and projects to recover from the condition of deficit. The Individual is mobilized even in those discourses countering the blended form school. Here, the blending is interpreted as a threat to the freedom of teaching and individuality, conceived in a closed and anti-technological way. Particularly in the case of the opponents, a clear separation is drawn between the 'human' and the 'technical'.

The pandemic has been then a test for alternative forms of schooling. It is not clear enough if the experimentation will alter the standard form permanently. The digital has been pervasively introduced in the technical infrastructure of many educational systems. Nevertheless, it remains to be seen if a purely or blended form prevails. Investigations during this time of crisis (Brehm et al., 2021; Grek \& Landri, 2021) suggest that digitalization has interested mainly the most affluent countries with growing inequalities within and across countries. Perhaps, the purely digital school will not be an option, at least for mass schooling. However, while the blended option looks at the new perspective, its concrete instantiations are not stable enough, as they are still enmeshed in the debate of emergency education.

\section{CONCLUSIONS}

Covid19 has been a shock for the systems of education all over the world. The protective measures, and in particular, the regime of social distancing, have problematized the configuration of schooling. School closure has interested many countries, so that millions of students could not attend educational activities, some- 
times for a longer time. The most severe educational crisis since WWII has consequently been experimented in Europe and beyond. By drawing on recent investigations on the dynamics and the effects of the pandemic in education (Brehm et al., 2021; Grek \& Landri, 2021), this article has tried to offer a description of the contemporary processes of institutional repairing. Overall, these reconfigurations have not completely reinvented the landscape of education but have accelerated several dynamics.

Research findings illustrate the installation of a state of education emergency leading to a swift digitalization of education. This acceleration accentuated the entanglement of public education into private owned and commercial platforms and paved the way to the emergence of the blended school form.

The increase entanglement was prepared by the dynamics of soft privatization that are strongly related to the mechanism of EU governance. Soft privatization describes the informal entanglement of associations, think-tanks, technological providers in the policymaking and the delegation to the non-state agencies of public operations (Cone \& Brøgger, 2020). The state of emergency has been a window of opportunity to accelerate the process of development of public and private partnerships. With the launch of the Global Education Coalition by UNESCO, hundreds of organizations were involved: Ed Tech companies, OECD, World Bank, non-profit organizations. While this collaboration appears inevitable, as the immediate movement to the digital required an extraordinary effort, it sets the conditions for the development of pandemic networks and the enlargement of the technological markets toward education (Williamson \& Hogan, 2020). As we have highlighted, however, this process can follow diverse trajectories so that the public and the private partnership can be more or less balanced. In Italy, Sweden and Germany, the pandemic translated into an opportunity for the unfolding of a digital market in education. School closures see the mobilization of Ed Tech providers to accelerate digitalization through philanthropic initiatives. Free software, webinars, LMS rapidly expanded. Some actors, like the Swedish Edtech Industry, actively promote digital platforms: it displayed the capacity of companies to fix the educational crisis. Public institutions in collaboration with private actors, like in the case of the Ministry of Education's Distance Education Initiative in Italy, promoted the widespread use of the digital to deal with the impossibility of doing school as usual. The growing entanglements of public and partnerships illustrated how Ed Tech providers, and notably their digital platforms, became in those countries and elsewhere obligatory points of passage in the ecology of education practice. This asymmetry is striking compared with other initiatives promoting non-profit, state-led projects, like Schul-Cloud in Germany and KlasCement in Belgium. The case of KlasCement reveals, however, that digitalization does not necessarily lead to the full privatization of schooling: the public can still assume a role of regulation promoting the active role of teachers and school and the development of more balanced relationships among public and private actors.

School closure was compensated by many solutions of emergency education. Some of these solutions draw on TV, radio, while others more on digital devices, giving rise to complex interactive online platforms. Globally, it has been observed a notable worldwide download of Learning Management Systems and the use of video platforms for synchronous operations. In the richest countries, there has been a massive adoption of digital interactive devices (Brehm et al., 2021). Some platforms have doubled their presence in the market in comparison with their competitors (Google Suite, for example) (Perrotta, Gulson, Williamson \& Witzenberger, 2021). In the temporary suspension of the transnational governance, the state of education emergency acted as an active promoter of the digital market, putting in most cases the premise for unbalanced public and private relationships. Accordingly, there is the concrete possibility that in the post-pandemic emerging configurations big Ed-Tech providers are destined to become more and more 'irreplaceable' in the technical infrastructure of educational systems. In the most affluent countries, the swift digitalization has led, therefore, to the increasing platformization and datafication of education.

Finally, some alterations of the basic form of schooling have been experimented. In the most rigid lockdown, it has led to purely digital schooling. Investigations realized during this time, however, have displayed how this experimentation exacerbate existing inequalities. Parents familiarity with ICT are strongly class-based oriented; that is, low socio-economic families have likely suffered more than high socio-economic families. High socio-economic families can draw on better resources, technologies, infrastructures but also on a reconfiguration of family settings to mitigate the school closure, as is demonstrated in the French case here presented (Delès, 2021). The emergence of the blended school form seemed to offer a more inclusive, suitable and equitable alternative. Even in that case, however, this form is not stable, as it is still open to many possible instantiations. We have described its emergence in the Italian case, and at the same time, illustrating the possible reconfigurations. The 'blending' reshapes the spaces and the times 
of the school, by intervening as well on the making of subjectivities. While the dynamics can be seen in other European countries, additional research is needed to understand the stabilization of this form: in particular, whether it is destined to substitute the standard form, to co-exist with it or to be abandoned to resume the basic form of schooling.

Broad investments in the digital give the direction of recovery strategy of the post-pandemic scenario. Nevertheless, the experimentation of new forms of schooling occurred in a state of emergency. The acceleration of the 'digital' was forced by the immediate need to find a temporary institutional repair. It was not the outcome of a mindful process of reinvention of the ecology of education practice. The association 'digital education' with 'state of emergency' can prevent to explore the possibilities of considering the 'digital' as an ordinary and fruitful ingredient of the school architecture. Therefore, it remains to be seen how the foreseen investments will affect the education systems in the long run and change in practice the future scenarios of schooling.

\section{REFERENCES}

Boltanski, L. (2011). On Critique. A Sociology of Emancipation. Cambridge and Malden, Policy Press.

Brehm, W. C., Unterhalter, E., \& Oketch, M. (Eds.). (2021). States of emergency: Education in a Time of Covid-19 (Vol. 50). https://doi.org/10.7748/ns.14.9.59.s53

Cone, L., \& Brøgger, K. (2020). Soft privatization: mapping an emerging field of European education governance. Globalization, Societies and Education, 18(4), 374-390. https://doi.org/10.1080/14767724.2020.1732194

Cone, L., Brøgger, K., Berghmans, M., Decuypere, M., Förschler, A., Grimaldi, E., ... Vanermen, L. (2021). Pandemic Acceleration: Covid-19 and the emergency digitalization of European education. European Educational Research Journal. https://doi. org/10.1177/14749041211041793

Delès, R. (2021). Parents for whom school is not that big a deal'. Parental support in home schooling during lockdown in France. European Educational Research Journal, 20(5), 684-702. https://doi. org/10.1177/14749041211030064

Dimopoulos, K., Koutsampelas, C., \& Tsatsaroni, A. (2021). Home schooling through online teaching in the era of COVID-19: Exploring the role of home-related factors that deepen educational inequalities across European societies. European Educational Research Journal, 20(4), 479-497. https://doi. org/10.1177/14749041211023331
Grek, S., \& Landri, P. (2021). Editorial: Education in Europe and the COVID-19 Pandemic. European Educational Research Journal, 20(4), 393-402. https://doi. org/10.1177/14749041211024781

Grimaldi, E., Landri, P., \& Taglietti, D. (n.d.). Una sociologia pubblica del digitale a scuola. https://doi. org/10.12828/97096

Kelly, P., Hofbauer, S., \& Gross, B. (2021). Renegotiating the public good: Responding to the first wave of COVID-19 in England, Germany and Italy. European Educational Research Journal, 20(5), 584-609. https:// doi.org/10.1177/14749041211030065

Landri, P. (2018). Digital Governance of Education. Technologies, Standards and Europeanization of Education. Bloomsbury.

Lindblad, S., Wärvik, G. B., Berndtsson, I., Jodal, E. B., Lindqvist, A., Messina Dahlberg, G., ... Wyszynska Johansson, M. (2021). School lockdown? Comparative analyses of responses to the COVID-19 pandemic in European countries. European Educational Research Journal, 20(5), 564-583. https://doi. org/10.1177/14749041211041237

Maulini, O., \& Perrenoud, P. (2005). La Forme Scolaire de l'Éducation de Base : Tensions Internes et Évolutions. In O. Maulini \& C. Montandon (Eds.), Les formes de l'éducation: variété et variations (pp. 147-167). De Boeck Supérieur.

Milner, A. L., Mattei, P., \& Ydesen, C. (2021). Governing education in times of crisis: State interventions and school accountabilities during the COVID-19 pandemic. European Educational Research Journal, 20(4), 520-539. https://doi.org/10.1177/14749041211022198

Mitescu-Manea, M., Safta-Zecheria, L., Neumann, E., Bodrug-Lungu, V., Milenkova, V., \& Lendzhova, V. (2021). Inequities in first education policy responses to the COVID-19 crisis: A comparative analysis in four Central and East European countries. European Educational Research Journal, 20(5), 543-563. https:// doi.org/10.1177/14749041211030077

Morozov, E. (2019). Digital Socialism? New Left Review, 33-68.

Nóvoa, A., \& Alvim, Y. (2020). Nothing is new , but everything has changed: A viewpoint on the future school. PROSPECTS, (0123456789). https://doi. org/10.1007/s11125-020-09487-w

Perrotta, C., Gulson, K. N., Williamson, B., \& Witzenberger, K. (2021). Automation, APIs and the distributed labour of platform pedagogies in Google Classroom. Critical Studies in Education, 62(1), 97-113. https://doi.org/10.1080/17508487.2020.1855597

Souto-Otero, M., \& Beneito-Montagut, R. (2016). From governing through data to governmentality through 
data: Artefacts, strategies and the digital turn. European Educational Research Journal, 15(1), 14-33. https://doi.org/10.1177/1474904115617768

Taglietti, D., Landri, P., \& Grimaldi, E. (2021). The big acceleration in digital education in Italy: The COVID-19 pandemic and the blended-school form. European Educational Research Journal, 20(4), 423-441. https://doi.org/10.1177/14749041211021246

Tesar, M. (2020). Towards a Post-Covid-19 'New Normality?': Physical and Social Distancing, the Move to Online and Higher Education. Policy Futures in Education, 18(5), 556-559. https://doi.org/10.1177/1478210320935671

Tyack, D., \& Tobin, W. (1994). The "Grammar" of Schooling: Why Has it Been so Hard to Change? American Educational Research Journal, 31(3), 453-479.

Williamson, B. (2016). Digital education governance: data visualization, predictive analytics, and 'real-time' policy instruments. Journal of Education Policy, 31(2), 123141. https://doi.org/10.1080/02680939.2015.1035758

Williamson, B., \& Hogan, A. (2020). Commercialization and privatization in / of education in the context of Covid-19 About the authors. 